\title{
A Visão Científica Evolucionista Interpela a Fé em Deus Criador
}

\author{
Alfonso García Rubio
}

A tensão entre ciência moderna e fé cristã vem de longa data. Como é bem sabido, a ciência experimental moderna foi, progressivamente, criticando e substituindo a visão clássica do mundo e do ser humano. Justamente, a visão que vem sendo utilizada pela teologia cristã para expressar e tematizar a fé em Deus criador e salvador. E, uma vez que a fé parecia identificada com a visão antiga e medieval, junto com esta visão, foi rejeitada a própria fé. Começou, assim, o lamentável mal-entendido que perdura até nossos dias.

Apesar de constatarmos alguns avanços no diálogo entre ciência e fé (mais concretamente, entre visão evolucionista e fé em Deus criador), o conflito continua vivo na atualidade. E continua sendo necessária a reflexão serena sobre o tema. Neste trabalho, num primeiro momento, limitar-me-ei a apresentar o estado da questão no que se refere à relação entre visão evolucionista e fé cristã em Deus criador. Isto será feito de maneira muito sucinta, porque se trata de algo bastante conhecido. No segundo item, também de modo resumido, acenarei para a distinção hermenêutica entre fé e expressão cultural da fé por ser básica para a superação fecunda do conflito. E, no terceiro item, serão apontadas algumas pistas teológicas que hoje estão sendo desenvolvidas na tentativa de responder ao desafio da visão evolucionista. 


\section{O conflito entre fé e ciência evolutiva: panorama atual}

A ciência nos fala da origem da vida e do universo, numa perspectiva evolucionista ${ }^{1}$. Trata-se de uma explicação aceita hoje, entre os cientistas, de maneira quase universal. A evolução, conforme a visão neo-darwiniana, implica: 1. Grande quantidade de acidentes, de mudanças aleatórias, não dirigidas (o acaso). 2. O mecanismo da seleção natural, cego, cruel, brutal, desapiedado (a necessidade). 3. Exigência de uma enorme quantidade de tempo, para tornar possível o processo evolutivo ${ }^{2}$.

E qual é atitude dos cientistas que defendem o evolucionismo em relação à fé em Deus criador? Vejamos de maneira muito resumida:

a) Rejeição total fundada na opção pela visão meramente materialista em conexão com o cientismo (só é aceito como verdadeiro aquilo que pode ser comprovado cientificamente) e com o ateísmo, mais ou menos militante ${ }^{3}$.

b) A opção pelo agnosticismo (não podemos saber se existe ou não um Deus criador) ${ }^{4}$.

c) A atitude de abertura dialógica (aceitação do pluralismo epistemológico ${ }^{5}$ ).

A pergunta é inevitável: diante da explicação evolucionista da vida e do universo, onde fica a afirmação de um Deus criador bom e providente? Vejamos, agora, as atitudes dos crentes cristãos face à visão evolucionista ${ }^{6}$ :

\footnotetext{
${ }^{1}$ Para uma breve explicação, dirigida aos não especialistas, sobre a visão atualmente predominante entre os astrofísicos e os biólogos a respeito da origem do universo e da vida, podem ser consultados, entre outros textos, COLlinS, F. S., A linguagem de Deus. São Paulo, Ed. Gente, 2007, ed. 4, p. 65- 90 e 91-114; TREVIJANO E., M., Fe y ciencia. Antropología. Salamanca, Sígueme, 1997, p.101-129 e 131-158.

${ }^{2}$ Nestes três pontos resume J. F. HAUGHT a teoria evolucionista tal como defendida atualmente. Cf. Id,. Cristianismo e ciência, Para uma teologia da natureza. São Paulo: Paulinas, 2010, p. 125-127. Este autor é um dos teólogos que mais tem estudado a problemática suscitada pelo evolucionismo em relação à fé em Deus criador.

${ }^{3}$ Cf., por exemplo, DAWKINS, R., Deus, um delírio. São Paulo: Companhia das letras, 2007. Para uma crítica, do ponto de vista filosófico, do positivismo/cientificismo, cf. SEGUNDO, J. L., Que mundo? Que homem? Que Deus. Aproximações entre Ciência, Filosofia e Teologia. São Paulo: Paulinas, 1995, 11-27.

${ }^{4}$ Cf. COLLINS, F. S., A linguagem de Deus, op. cit., p. 165-175.

${ }^{5}$ Cf. HAUGHT, J. F., Deus após Darwin. Uma teologia evolucionista. Rio de Janeiro: José Olympio, 2002, p. 79-104.

${ }^{6}$ Os autores que tratam da relação entre fé cristã e evolucionismo utilizam distintas categorias para focalizar as diferentes atitudes tanto de cientistas quanto de teólogos. Assim, o físico e teólogo IAN G. BARBOUR, When Science Meets Religion. Enemy, Strangers, or Partners?, NY: Harper Collins Publishers Inc., 2000, divide as distintas maneiras de relacionar-se a ciência e a religião utilizando as categorias de conflito, independência, diálogo e integração. Já J. F. HAUGHT, op. cit., p. 167-188, estabelece a seguinte tipologia: fusão (confusão de métodos), contraste (perguntas distintas que não interferem mutuamente), contato (implicações da ciência para a teologia) e confirmação (a teologia pode justificar a confiança no traba-
} 
1. Primeiramente, estão aqueles que defendem a incompatibilidade radical entre o evolucionismo e a fé em Deus criador. É o caso do chamado criacionismo: leitura literal dos relatos bíblicos sobre a criação. A versão atual mais extrema: "Criacionismo da Terra Jovem" (Young Earth Criationism -(YEC) ${ }^{7}$.

Podemos colocar também aqui a explicação "fixista" que defende a criação de cada espécie viva, no início, por separado e de maneira imutável.

2. Tendências concordistas: procuram compatibilizar os resultados das investigações científicas com as expressões da fé em Deus criador. Duas merecem destaque especial:

-“Intelligent Design" ID, (Desígnio Inteligente): defende a existência de uma Mente inteligente atuando no universo desde seu início e dotando-o de sentido ${ }^{8}$. -O "Princípio Antrópico": o acaso seria incapaz de explicar a série fantástica de coincidências requeridas para o aparecimento da vida. Princípio antrópico em sentido débil: tudo parece ter sido feito como se uma Mente tivesse dirigido a evolução para o aparecimento da vida e do ser humano. Princípio antrópico em sentido forte: o universo existe para tornar possível a existência de seres humanos ${ }^{9}$.

-Discernimento: a respeito destas explicações, convém chamar a atenção para a necessária prudência do teólogo. Cuidado com o "Deus das lacunas" ou o "Deus tapa-buraco"! De fato, parece exagerado o entusiasmo de alguns teólogos diante da explicação da origem do universo mediante o Big Bang, ou em relação à física quântica, a respeito da visão sistêmica ou do pensamento complexo etc. É verdade que estas e outras perspectivas da ciência tornam o ar cultural mais respirável e abrem a possibilidade de um certo

lho científico). Para uma boa introdução sobre as relações entre ciência e teologia, ver o trabalho do também físico e teólogo, J. POLKINGHORNE, Ciência y Teologia. Una introdución. Santander: Sal Terrae, 2000. A complexa natureza da realidade com seus distintos estratos, que podem e devem ser integrados, é estudada por este mesmo autor na procura de um diálogo fecundo entre teologia e ciência, em: Id., Explorar la realidad. La interrelación de ciencia y religión. Santander: Sal Terrae, 2007. Pode também ser consultada com proveito a obra do bioquímico e teólogo A. PEACOCKE, Los caminos de la ciencia hacia Dios. El final de toda nuestra exploración. Santander: Sal Terrae, 2008.

7 Ver um resumo das teses básicas do "Criacionismo da Terra Jovem" em: COLLINS, F. S., A linguagem de Deus, op. cit., p.178-185. Sobre o criacionismo, cf. também HAUGHT, J. F., Cristianismo e Evolução em 101 perguntas e respostas. Lisboa: Gradiva, 2009, p. 125-146.

${ }^{8}$ Para uma crítica do "Desígnio Inteligente", cf. HAUGHT, J. F., Deus após Darwin, op. cit., p. 15-25; Id., Cristianismo e Evolução, op. cit., p. 149-167; COLLINS, A linguagem de Deus, op. cit., p. 187-202.

${ }^{9}$ Sobre o "princípio antrópico", cf. BARROW, J. e TIPLER, F., The Anthropic Cosmological Principle. Oxford: Clarendon Press, 1986; COLLINS, A linguagem de Deus, op. cit., p.79ss. 
diálogo entre teologia e visão científica evolucionista. Mas, convém ressaltar: a fé em Deus criador não depende de nenhuma prova científica ${ }^{10}$.

3. Tentativas de delimitar cuidadosamente aquilo que é próprio da investigação científica e aquilo que é específico da reflexão teológica. Os defensores desta atitude procuram manter uma total separação entre os mundos da ciência e da fé. De fato, os objetos formais e os métodos são muito diferentes.

Com efeito, o cientista trabalha realidades do mundo, do universo e do ser humano, no âmbito da evidência empírica, realizando reiteradas experiências, verificações e comprovações, deixando de lado toda preocupação com o Transcendente (ateísmo metodológico). O objetivo do cientista é explicar o como e o quando dos eventos naturais.

O teólogo, por sua vez, trabalha sobre os enunciados da fé e sobre a experiência da fé. O objeto da teologia é sempre Deus. As realidades do mundo e do ser humano fazem parte também do seu objeto, mas na medida em que referidas a Deus. Há conhecimento na experiência de fé, mas de ordem distinta do conhecimento científico. Certamente, a teologia utiliza a razão e a linguagem crítica e sistematicamente ordenada, mas dista muito das comprovações do método próprio da pesquisa científica. $\mathrm{O}$ teólogo procura, à luz da fé cristã, o porque e o para que da vida humana e do cosmos, o sentido último e mais profundo da realidade.

Nessa delimitação do campo da ciência e do campo próprio da fé, podemos apresentar também a atitude de numerosos teólogos e autoridades da Igreja que aceitam que Deus pode criar o universo e a vida, mediante a evolução. Mas, não tiram as conseqüências dessa aceitação.

-Discernimento: Certamente, a delimitação dos campos e dos métodos de cada saber é muito necessária e elimina muitos falsos problemas. E mostra, positivamente, que a investigação científica e o trabalho teológico não têm porque entrar em conflito. Entretanto, essa delimitação não parece suficiente para responder ao desafio da relação entre teologia e ciência moderna. E se for levada longe demais, pode facilmente estabelecer um novo tipo de dualismo. Será que ciência e fé são duas linhas paralelas que nunca se encontram? ${ }^{11}$

4. Procura de uma "articulação de sentido" entre ciência evolutiva e fé em Deus criador, colaborando ambas na humanização do ser humano. Elas po-

\footnotetext{
${ }^{10} \mathrm{Cf}$. HAUGHT, Cristianismo e ciência, op.cit., p.157-188.

${ }^{11}$ Cf. GARCIA RUBIO, A., Unidade na pluralidade. O ser humano à luz da fé e da reflexão cristãs. Paulus, 2006, ed.4, p.365-366.
} 
dem se complementar e se enriquecer mutuamente. Aqui, é necessário aceitar que existem diferentes níveis no conhecimento da realidade (ciência, arte, ética, religião). No seu próprio nível, se dá um conhecimento verdadeiro e tem sentido cada explicação. Assim, é necessário superar o literalismo bíblico e científico. Cuidado com a tentação da extrapolação ${ }^{12}$.

Convém agora perguntar: não será necessária a articulação desses níveis, na unidade que é o sujeito, a pessoa? A complexidade do real não exige que cada saber específico esteja aberto dialogicamente aos outros saberes e que todos eles estejam inter-relacionados? Há necessidade de desenvolver a interdisciplinaridade e a transdisciplinaridade.

\section{O problema hermenêutico: distinção entre fé e expressão cultural da fé}

O recurso às distintas linguagens e aos métodos tão diferentes empregados pelo cientista e pelo teólogo é insuficiente para explicar o conflito vivido entre os homens da Igreja e os cientistas que defendem a visão evolucionista. Para ir até a raiz do conflito, é indispensável a ajuda da ciência hermenêutica. Hoje é sabido que a teologia utiliza o método hermenêutico: os enunciados da revelação bíblica e da grande tradição eclesial são interpretados de maneira que possam ter uma significação real para cada cultura e, no nosso caso, para a cultura contemporânea.

No campo da hermenêutica, é especialmente importante a distinção entre fé e expressão cultural da fé (incluindo também a expressão religiosa) ou entre fé e crença ${ }^{13}$. Sem dúvida, o objeto da fé é sempre transcendente, mas a fé é expressada, culturalmente, mediante conceitos e imagens, mediante uma determinada visão do mundo e do ser humano, mediante interpretações próprias das diferentes culturas...

-Grave risco: confundir a fé com uma determinada expressão da mesma. É o que acontece com o fundamentalismo, tanto religioso quanto científico.

-Explicitando um pouco mais a distinção entre fé e crenças (expressão cultural da fé), deve ser acrescentado, seguindo R. Haight ${ }^{14}$, que estas possuem importante função social, comunitária e individual, pois elas estruturam a identidade da comunidade e de cada pessoa. Assim, compreende-se que se dê uma tendência social e comunitária ao fundamentalismo. O motivo é ób-

\footnotetext{
${ }^{12}$ Cf. Ibid., p.363.

${ }^{13}$ Cf. HAIGHT, R., Dinâmica da teologia. São Paulo: Paulinas, 2004, p. 46-49.

${ }^{14}$ Cf., Ibid., p. 54.
} 
vio: na mudança da expressividade da fé, está em jogo a segurança e a identidade do indivíduo e da comunidade.

Mais ainda, quando a crença ou o ato religioso estão a serviço da expressão da fé, não são meras expressões, pois contêm a fé, de maneira imperfeita, mas realmente. Só que a fé não se esgota numa determinada expressão da mesma. As expressões religiosas e culturais da fé são condicionadas historicamente e não se identificam com ela. Certamente são importantes para a inculturação da fé, mas não possuem um valor absoluto, como pensam os fundamentalistas. Podem e devem revistas, quando muda a cultura.

Entretanto, é indispensável o discernimento e uma adequada pedagogia pastoral. Crenças não se mudam por decreto. É necessário um lento e progressivo trabalho de conscientização, desenvolvido normalmente em pequenas comunidades, para ajudar o cristão a perceber e a assumir a eventual necessidade de mudança na expressão da fé, precisamente para guardar fidelidade à intencionalidade profunda dela.

Auxiliados pela hermenêutica, podemos retomar, agora, o tema da tensão entre a fé em Deus criador e a visão evolucionista. Será fácil identificar o núcleo do problema. Com efeito, a fé no Deus criador foi expressada e tematizada mediante uma determinada cosmovisão tomada do pensamento filosófico clássico, especialmente aristotélico. E, no decurso dos séculos, essas expressões e interpretações (crenças) foram ficando quase identificadas com a fé na criação. Daí a reação das autoridades da Igreja e dos cristãos, em geral, diante das afirmações da ciência moderna.

Importa muito ressaltar que, na medida em que a expressão cultural da fé ou crença acaba praticamente se identificando com o conteúdo mesmo da fé, se desenvolve uma forte oposição à nova visão do mundo defendida pela ciência e que desautoriza a cosmovisão antiga e, com ela, a fé que estava unida a essa expressão cultural. $\mathrm{O}$ caso G. Galilei ilustra bem essa problemática.

Aplicando a distinção entre fé e expressão cultural da fé aos relatos bíblicos sobre a criação, surge logo a pergunta: então, qual é a mensagem contida neles? Certamente, vem afirmado que o fundamento de tudo quanto existe, especialmente o ser humano, está na ação criativa amorosa de Deus. Obviamente, a fé em Deus criador é expressada mediante a visão do mundo e do ser humano própria da época em que esses relatos foram elaborados e redigidos (expressão cultural). Eles não apresentam uma explicação do como se realiza a ação criadora divina ${ }^{15}$.

\footnotetext{
${ }^{15}$ Em conexão com essa afirmação fundamental, a mensagem dos relatos bíblicos da criação contém outras afirmações sobre Deus e sobre o ser humano de grande relevância. A bibliografia sobre este tema é muito extensa. Eu mesmo já fiz uma ampla explicitação desse conteúdo, cf. GARCÍA RUBIO, A., Unidade na pluralidade, op.cit., p. 149-168.
} 
A explicação sobre a maneira como se realiza essa ação criadora fica em aberto: explicação fixista ou evolucionista?

\section{Aceita a perspectiva evolutiva, como repensar a expressão cultural da fé em Deus criador? Algumas pistas:}

Por que numerosos cientistas e filósofos rejeitam a existência do Deus criador? O teólogo, oportunamente, pode responder com outra pergunta: que Deus é rejeitado? Certamente, trata-se do Deus da filosofia tradicional e das religiões, em geral. Trata-se do Deus Soberano e Senhor absoluto, diante do qual o ser humano e as realidades do mundo investigadas pela ciência aparecem inconsistentes, praticamente ficando reduzidos a nada.

Diante desse Deus Onipotente, onde fica a autonomia do ser humano? Onde fica a autonomia das leis evolutivas? Na medida em que o homem e a mulher modernos vão se descobrindo como sujeitos dotados de independência e autonomia interior, a fé nesse Deus Todo-poderoso entra em crise. Reaparece o antigo conflito entre a Soberania absoluta desse Deus e a realidade da liberdade e autonomia do ser humano. Algo semelhante acontece com o cientista. Ele estuda a evolução e as leis evolutivas e vai percebendo que elas se explicam por elas mesmas, sendo desnecessária uma intervenção exterior, transcendente, sobrenatural.

Não vou focalizar aqui as tentativas de resposta que, utilizando a razão, têm sido dadas à dificuldade para articular a total soberania de Deus e a autonomia humana e das leis que regem o universo. Só desejo ressaltar onde se encontra uma intuição fundamental do ateísmo moderno, a saber: a defesa da autonomia do sujeito humano e das leis da natureza é que leva à crise na fé em um Deus onipotente, criador e providente.

Isto suposto, o teólogo interessado no diálogo crítico com os cientistas que defendem a evolução da vida e do universo, continua perguntando: esse Deus rejeitado pelo cientista e pelo filósofo é o mesmo Deus revelado por Jesus Cristo? Devemos reconhecer que, historicamente, houve uma quase identificação entre o Deus da razão, tomado do pensar filosófico grego, e o Deus de Jesus Cristo, o Deus que se revela na história humana e no cosmo. A história da teologia cristã mostra o quanto resultou difícil articular o Deus onipotente, impassível, imutável etc. com o Deus compassivo, misericordioso, com o Deus da Encarnação, revelado na vida-cruz-ressurreição de Jesus de Nazaré.

Conscientes de que só mediante Jesus Cristo temos acesso ao Deus cristão (cf. Jo 1,18), os teólogos que dialogam com o evolucionismo procu- 
ram repensar a fé em Deus criador a partir desse Deus revelado em e por Jesus Cristo.

Vejamos, então, como é que está sendo desenvolvida a reflexão sobre o Deus criador tendo em conta, por um lado, a visão do cientista (e do filósofo) sobre a autonomia das leis evolutivas e, por outro, a revelação de Deus mediante Jesus Cristo. Trata-se apenas de pistas apresentadas aqui muito sumariamente. Cada uma delas exige um desenvolvimento e um aprofundamento que não é possível realizar, neste pequeno artigo. São suficientes, contudo, para que apareçam, com bastante clareza, as linhas mestras da reflexão teológica atual sobre a abrangente temática do evolucionismo, em relação à fé em Deus criador.

1. O Deus criador, na perspectiva cristã, é um Deus, relacional, Trindade, um Deus que em si mesmo é Amor. Quando levada a sério esta afirmação de fé, surge a necessidade de superar uma imagem de Deus excessivamente tributária do pensar filosófico grego. Para este, Deus é visto como natureza divina, com seus atributos correspondentes: onipotência, imutabilidade, impassibilidade etc. Um Deus certamente impessoal. Pois bem, nesse ambiente, irrompe a grande novidade cristã: a relação, desprezada como desprovida de realidade própria (ens in alio), é tão divina quanto a substância! Mais ainda, o ser mesmo de Deus é relacional ${ }^{16}$.

A teologia atual, no diálogo crítico com a visão evolucionista, recupera a percepção de que o Deus criador é o mesmo Deus-Trindade, Deus relacional. E, assim, a fé em Deus criador é repensada a partir das relações trinitárias, relações mútuas de amizade e de comunhão ${ }^{17}$. Entende-se bem que um Deus relacional crie um mundo de mútuas relações, tal como é apresentado pela biologia evolutiva. Mais ainda, um Deus relacional nada tem em comum com o Deus Grande Arquiteto ou Relojoeiro do universo (deísmo), um Deus que cria a realidade toda pronta, acabada. O Deus relacional cria, realmente, mas não se relaciona com o mundo criado de maneira controladora, impositiva, dominadora, manipuladora. A seguir, veremos isto de maneira mais direta.

2. O Deus relacional, que em si mesmo é amor, leva a repensar a imagem do Deus onipotente desvinculado do Amor. Primeiramente, nesta revisão da imagem de Deus, é fundamental se perguntar sobre o significado e a eficácia

${ }^{16}$ Cf. RATZINGER, J., Introdução ao cristianismo. Preleções sobre o Símbolo Apostólico. São Paulo: Herder, 1970, p.141.

${ }^{17}$ Cf. EDWARDS, D., El Dios de la evolución. Una teologia trinitaria. Santander: Sal Terrae, 2006. 
do poder verdadeiro. Pois temos a tendência a projetar em Deus a nossa compreensão do poder, entendido como controle e domínio. Em contraste total com essa visão do poder, deparamo-nos com o poder de um Deus $h u$ milde, revelado mediante Jesus Cristo (cf. Fil 2,6-11; 2Cor 8,9...). Mas, entenda-se bem, não se trata de que o Deus de Jesus Cristo seja impotente! Se assim fosse, não poderia nos salvar! O que acontece é que a onipotência do Deus, que é Amor, vem expressada na desconcertante auto-doação e no "esvaziamento" totalmente livre que é a encarnação ${ }^{18}$.

Ora, o Deus da encarnação é o mesmo Deus da criação. Nesta, encontramos o mesmo dinamismo kenótico. Por Amor, o Deus naturalmente onipotente, pode, livremente, deixar espaço real para a autonomia da criatura e do dinamismo evolutivo. Se Deus decide criar um mundo em evolução, respeita sempre as leis evolutivas, não intervém pontualmente, nem manipula o devir evolutivo ${ }^{19}$. A criação é algo muito distinto de fazer ou fabricar coisas prontas. Conforme o teólogo A. Gesché, Deus é tão criador que "faz com que as coisas se façam como elas se fazem" 20 . Deus cria um mundo com potencial criativo para que possa se desenvolver a partir de si próprio. Ele "criou um processo, virtualidades"... "um cosmo dinâmico e inventivo"21.

3. Superação da imagem de um Deus que age na criação-evolução "desde fora". Quer dizer, trata-se de superar a visão de um Deus intervencionista ${ }^{22}$. $\mathrm{O}$ agir de Deus na criatura e na evolução é sempre incessante e transcendental. Não se trata de uma ação junto a outras ações, mas do fundamento transcendental de toda causalidade criada, sem nenhuma interrupção na concatenação das causas intra-mundanas.

O influxo transcendental e não categorial de Deus, no interior do processo evolutivo, possibilita e fundamenta a auto-transcendência e autosuperação presentes no devir evolutivo (K. Ranher) ${ }^{23}$ bem como sua capacidade interna de auto-organização. A ação de Deus realiza-se sempre de maneira transcendental, no interior mesmo da causalidade finita. Nada é tirado

\footnotetext{
${ }^{18}$ Cf. HAUGHT, J. F., Cristianismo e ciência, op. cit., p. 69-73 e 260-265; Id., Deus após Darwin, op.cit., p. 138-141; SEGUNDO, J. L., Que mundo? Que Homem? Que Deus?, op. cit., p.326- 327 e 393.

${ }^{19}$ Cf. HAUGHT, J. F., Deus após Darwin, op. cit., p. 138-141; Id., Cristianismo e ciência, op. cit.., p.135-140.

${ }^{20}$ GESCHÉ, A., O Cosmo. São Paulo: Paulinas, 2004, p. 62.

${ }^{21}$ Ibid., p. 65.

${ }^{22}$ Cf. QUEIRUGA, A. T., Recuperar la creación. Por una religión humanizadora. Santander: Sal Terrae, 1996 p. 93ss.; Id., Fin Del cristianismo premoderno. Retos hacia un nuevo horizonte. Santander: Sal Terrae, 2000, p. 30ss. (Há tradução desta obra em português)

${ }^{23}$ Cf. RANHER, K., Teología y ciencias naturales. Madrid:Taurus, 1967, p. 130-131.
} 
da autonomia própria da criatura ou das leis evolutivas. Pelo contrário, a ação divina torna possível essa auto-superação bem como o dinamismo evolutivo, como um todo. Sim, para a pessoa de fé, a explicação última do processo evolutivo é a criação divina. Isto não desautoriza a verdade contida nos níveis científicos (nível físico-químico, nível da herança genética, nível da seleção natural... $)^{24}$.

4. Revisão da imagem do Deus bom, criador e providente diante do tremendo desafio do mal. No processo evolutivo, conforme a visão científica evolucionista, quanta luta, violência, destruição e caos pode ser constatado! Como um Deus bom pode criar um mundo onde a violência e a destruição estão tão fortemente presentes?

A resposta da teodicéia tradicional e da primeira modernidade (o deus do deísmo) pode ser assim resumida: na finitude da criatura, encontra-se a explicação racional do mal. Deus fica, assim, inocentado da existência do mal (Leibniz, Espinosa, Enciclopedistas, Kant, Hegel...) ${ }^{25}$. Contudo, não basta afirmar, racionalmente, que a finitude é a causa do mal, pois o problema é sobretudo existencial ${ }^{26}$.

A resposta da Segunda Modernidade, a modernidade da suspeita: o anúncio da morte de Deus e, posteriormente, da morte do homem. De fato, num primeiro momento, o ateísmo propugna a morte de Deus para que o ser humano possa viver, como ser humano (Feuerbach, Marx, Nietzche, Freud...). Num segundo momento, desenvolve-se a antropologia da morte do homem (Foucoult, Levi-Straus...). O ser humano é que é acusado da existência da mal. Só que, como faz notar A. Gesché, sem Deus, o ser humano fica esmagado pelo peso do mal! $!^{27}$

Terceira Modernidade (Pós-modernidade): nova procura do divino. Não estará despontando uma nova modernidade, que não quer nem a morte de Deus nem a morte do homem?, pergunta-se o mesmo A. Gesché. E não será necessário, acrescenta, que Deus viva para que o homem possa viver? ${ }^{28}$

Porém, de quê Deus se trata? Pois a procura atual pelo divino é bastante confusa. Então, onde encontrar o Deus verdadeiro? Na luminosidade

\footnotetext{
${ }^{24}$ Interessante resulta a analogia que J. F. HAUGHT estabelece entre o aspecto informacional da vida e a atuação do Espírito na evolução: cf. Id., Cristianismo e ciência, op. cit., p. 207-209.

${ }^{25}$ Cf. GESCHÉ, A., O Mal, em: Id., Deus para pensar. São Paulo: Paulinas, 2003, p. 154.

${ }^{26}$ Cf. ESTRADA, J. A., A impossível teodicéia. A crise da fé em Deus e o problema do mal. São Paulo: Paulinas, 2004.

${ }^{27}$ Cf. GESCHÉ, A., O Mal, op. cit., p.36 e 154-159.

${ }^{28}$ Cf. Ibid., p. 38 e 160.
} 
racional ou no escândalo da cruz ${ }^{29}$ No poder imperial ou na cruzressurreição? No poder coercitivo ou no poder persuasivo?

A atitude de Deus em relação ao mal vem expressada em Jesus Cristo, Deus feito limitação humana (cf. Jo 1,14), submetido às limitações do mal (cf. Heb 4,15), mas sempre em oposição ao mal e do lado das vítimas. O mal é para ser combatido. Percebemos, a partir de Jesus Cristo, que a luta de Deus contra o mal não se dá mediante discursos, mas assumindo-o e, assim, vencendo-o, desde dentro. Deus é o primeiro a lutar contra o mal.

Em sintonia com esse Deus, hoje, o mal vai sendo vencido, de maneira limitada, mas real, mediante a prática da justiça, do amor efetivo e do cuidado responsável face ao cosmo.

5. Jesus Cristo e o Espírito Santo: Em sintonia com as cristologias recentes $^{30}$, os teólogos que procuram o diálogo com a visão evolucionista focalizam a figura histórica de Jesus de Nazaré, o dinamismo por ele vivido, decididamente aberto ao futuro escatológico, anunciador incansável da chegada do Reino de Deus, fiel ao caminho do serviço, assumido, desde o início de sua vida de pregador itinerante (batismo), culminando na morte-ressurreição. Fidelidade expressada também na rejeição do messianismo de poder dominador (tentação).

Em Jesus Cristo, encontramos a revelação de um Deus que não se impõe de modo coercitivo, que não violenta, porque é amor. Por isso, o caminho de Jesus é o serviço, até às últimas consequências (cf. Mc 10,45).

Recupera-se, igualmente, a cristologia cósmica. Jesus Cristo, depois da Páscoa, é confessado pela Igreja do século I, como Senhor universal, não só da humanidade, mas do cosmo em sua totalidade. Ele tem uma significação cósmica. Assim, Col 1, 15-20 ressalta a dimensão universal e cósmica da mediação criadora e salvadora do Senhor Jesus. Ele está atuando desde o início da criação e na continuação dela, encontrando-se presente, igualmente, na meta final da história e do cosmo. Ele é Princípio e Fim, Alfa e Ômega (cf. Ap 21,6; 22,13). Ele é a plenitude e a recapitulação do universo (cf. Ef $1,10)$. Desde o primeiro instante da criação, até a consumação escatológica, o mundo criado encontra em Jesus Cristo sua mais íntima consistência e fundamentação. Mas, note-se bem, trata-se de um senhorio muito original: o Senhor é quem lava os pés dos discípulos! (cf. Jo, 13,12-17) ${ }^{31}$.

\footnotetext{
${ }^{29}$ Cf, Ibid., p. 161.

${ }^{30}$ Para citar apenas um exemplo: cf. SCHILLEBEECKX, E., Jesus: a história de um vivente. São Paulo: Paulus, 2008. Tradução feita a partir da $10^{\mathrm{a}}$ edição do original holandês.

${ }^{31}$ A respeito do significado de Jesus Cristo, no horizonte de uma visão evolucionista, merecem destaque especial Teilhard de Chardin, K. Rahner e J. Moltmann. O teólogo D. Edwards
} 
O caminho vivido por Jesus de Nazaré e a proclamação do seu senhorio cósmico são inseparáveis da presença e da atuação do Espírito. É guiado pelo Espírito que Jesus vive o messianismo de serviço. É no Espírito que ele é exaltado e vem afirmado o seu senhorio. É esse mesmo Espírito vivificador quem age no interior de cada ser humano, de cada criatura e do processo evolutivo $^{32}$.

6. Interpelação para a Igreja atual: em geral, os teólogos que procuram dialogar com a visão evolucionista não focalizam diretamente problemas eclesiológicos. Mas, uma vez que em Jesus Cristo, inseparável da atuação do Espírito, se revela o Deus original e desconcertante da Kénosis (revelação iniciada já na criação), o Deus que persuade com o amor, no pólo oposto de toda dominação e de toda coerção, segue-se que a Igreja será chamada, continuamente, à conversão a fim de tornar-se mais fiel a esse Deus e ao messianismo de serviço do Senhor Jesus.

Esta é uma proposta que, especialmente, a partir do Vaticano II, está em andamento (com não poucas resistências internas), na Igreja católica. Trata-se de uma profunda conversão eclesial: uma Igreja vista sobretudo como povo de Deus itinerante, ágil, humilde como seu Deus e seu Senhor Jesus, Igreja realmente servidora e que aprende, de fato, (não apenas nas pessoas mas, igualmente, nas suas instituições e estruturas), a colocar o amor e a misericórdia acima da lei e do direito. Uma igreja sinal vivo do Reino de Deus, reinado e senhorio universal, cósmico, e não apenas humano. Uma Igreja realmente aberta ao futuro, à Promessa, uma Igreja que vive a esperança ativa ${ }^{33}$. A aplicação ao trabalho pastoral é óbvia, pois o autoritarismo e a fixação no passado impedem, com freqüência a vivência do dinamismo evangélico e sua abertura ao futuro.

7. E o pecado original e a redenção? O "pecado original" é visto em relação com a profunda ambigüidade em que todos estamos imersos. Todo ser humano vem a este nosso mundo, começa já a existir, numa condição negativa,

faz uma breve apresentação crítica da cristologia evolucionista de cada um deles para apresentar, depois, um esboço de cristologia sapiencial: Jesus como Sabedoria de Deus atuando na criação. Cf. EDWARDS, D., El Dios de la evolución., op. cit., p.122-148.

${ }^{32}$ Cf. MOLTMANN, J., Deus na criação. Doutrina Ecológica da Criação. Petrópolia: Vozes, 1992, p. 27-41 e 150-157; Id., El Espíritu de la vida: una pneumatología integral. Salamanca: Sígueme, 1998; EDWARDS, D., El Dios de la evolución, op. cit., p. 96-121.

${ }^{33}$ De maneira especial, é criticado, no cristianismo atual, a predominância concedida ao passado, a forte tendência restauradora, a nostalgia de uma época imaginária de perfeição junto com a escassa importância concedida, praticamente, ao futuro. Ver, como exemplo, HAUGHT, J. F., Cristianismo e ciência, op. cit., p. 151-153. 
marcado pessoalmente pela rejeição humana ao apelo do Deus criadorsalvador para abrir-se ao dom do seu amor, para aceitar o convite para viver a liberdade, a criatividade e o amor. De fato, somos condicionados tanto pela abertura à vida e ao amor quanto pelo fechamento destruidor da vida, em todos os níveis. Condicionamento que nos afeta interiormente, pessoalmente. Amor e egoísmo andam juntos, na nossa vida. Acresce que o mal não está apenas na desordem destruidora da vida, mas, encontra-se, igualmente, na monótona repetição do mesmo, na omissão, em deixar as coisas e as situações como estão, rejeitando o apelo para a liberdade criativa e para a responsabilidade face à história e à evolução ${ }^{34}$.

Esta é uma situação que leva à experiência de que não somos capazes de nos libertar sozinhos, de que necessitamos da salvação de Deus. O mundo, resultado da evolução, é um mundo inacabado, imperfeito, a caminho de maior perfeição. Certamente, esta é também a situação do ser humano. E, assim, a redenção é vista, sobretudo, como libertação da nossa liberdade e da criatividade para, na ambigüidade da história, ir inventando soluções mais humanas e mais ecológicas para os desafios e os problemas que a história humana e a história da evolução suscitam. A Redenção, sem esquecer da dimensão de libertação do pecado, aponta para a "nova criação", para a reconciliação do universo, para a superação do mal e para a plenitude da vida e do amor $^{35}$. Redenção entendida não apenas referida aos seres humanos, mas, igualmente, ao conjunto da criação; redenção realmente universal, posto que atuando no universo desde o primeiro instante da evolução ${ }^{36}$.

Reconciliação e plenitude que estão já atuando, em germe, no meio da ambigüidade e nas contradições do mundo atual. Na fé cristã, se dá uma aposta pelo futuro do ser humano e do universo.

8. Redescoberta do Deus da Promessa e do Futuro de plenitude, fundamento de nossa esperança. Promessa e futuro extraordinariamente ampliados, posto que incluem também a história cósmica da criação.

Os teólogos que procuram dialogar com a visão científica evolucionista sabem que boa parte dos cosmólogos e astrofísicos são pessimistas, quando se trata do futuro do universo. Entretanto, é bom observar que o pessimismo sobre o futuro é uma conjetura, em grande parte derivada da tendência cientí-

\footnotetext{
${ }^{34}$ Cf. SEGUNDO, J. L., Que mundo? Que Homem? Que Deus? op. cit., p. 491-529. Sobre a reinterpretação do conteúdo do "pecado original", numa perspectiva evolucionista, pode ser consultada também a obra : GARCÍA RUBIO, A., Unidade na pluralidade, op. cit., cap.16, especialmente, p. 636-662.

${ }^{35}$ Cf. SEGUNDO, J. L., Que mundo? Que Homem? Que Deus? op. cit., p. 491-529.

${ }^{36}$ Cf. HAUGHT, J. F., Cristianismo e ciência, op. cit., p. 155-156.
} 
fica que leva a olhar para o passado, considerando-o como norma do presente. Mas, cabe aqui perguntar: por que não olhar para um futuro aberto, ainda desconhecido, que, como tem acontecido no passado, no processo evolutivo, pode trazer novidades desconcertantes? O cosmo, inacabado e imperfeito, dado que a evolução continua, não estará aberto a novas formas de perfeição e de complexidade? As surpreendentes conquistas realizadas até hoje pela evolução, sem deixar de lado a realidade da ambiguidade, do aleatório e da multiplicidade de experimentos fracassados, não estarão apontando para novas possibilidades, para novas e insuspeitadas inovações? Esta é outra conjetura plausível. Com ela, pode dialogar a perspectiva bíblica que apresenta os seres humanos e o cosmo abertos ao futuro, "um céu novo e uma terra nova" (Ap 21,1).

Entretanto, convém insistir: a fé cristã no Deus do Futuro e da Promessa não depende de uma explicação ou opinião científica. A fé no futuro de plenitude, de reconciliação universal encontra seu fundamento no Deus criador-salvador, com as características enumeradas acima. E, de maneira muito concreta, apóia-se no Deus da Vida que ressuscita Jesus, primícias do mundo novo ${ }^{37}$.

Polarizados por essa Promessa e por esse Futuro, redescobrimos a nossa condição peregrinante, sacudindo a instalação e o marasmo. Convém lembrar, com J. F. Haught, que o Deus da Bíblia vai sempre diante do seu povo e, também, vai diante da evolução, atraindo-a. Não é um Deus que a empurra desde o passado! O Deus cristão é um Deus da aventura, bem mais do que aquele que preserva o status quo! Somos chamados, assim, não a restaurar um passado de perfeição que nunca existiu, mas a viver a abertura ao futuro da "criação nova" ${ }^{38}$.

9. Obviamente, a imagem de Deus recuperada pelos teólogos que dialogam com a visão evolucionista leva a repensar o que significa a humanização do ser humano. Criado à imagem de um Deus relacional, o ser humano será valorizado sobretudo pela sua estrutura dialógico-relacional. E como, em Deus, o decisivo é a Liberdade, a Criatividade e o Amor, o ser humano será chamado, de maneira toda especial, a desenvolver a capacidade de se decidir com liberdade (condicionada, mas real), de amar e de criar algo novo na história e no cosmo. Será ressaltada a prioridade da liberdade e da criatividade sobre os determinismos da natureza. Não se trata de negar a natureza e os seus determinismos (a natureza é o alicerce necessário para que a dimensão

\footnotetext{
${ }^{37}$ Cf. Id., Deus após Darwin, op. cit., p.131-147; Id., Cristianismo e ciência, op. cit., p. 217246 e 265-269.

${ }^{38}$ Cf. Ibid., p.265-269.
} 
relacional, a liberdade responsável e a criatividade possam se desenvolver). Fazem parte do processo evolutivo, também no ser humano. Este tem de aprender a aceitá-los e a lidar com eles, mas, consciente de que o decisivo, a última palavra é da liberdade para a criatividade e o amor ${ }^{39}$. Em resumo, o ser humano é chamado a se fazer, a tornar-se alguém capaz de viver a liberdade responsável, criativa e amorosa

Convém lembrar aqui, com A. Gesché, que para a fé bíblico-cristã, no início da criação, está o Deus criador e, destarte, a liberdade, e não a fatalidade, é que guia o cosmo e a história humana. É verdade que, conforme mostra a ciência, a natureza, o acaso e a necessidade fazem parte do processo evolutivo, mas, no início, está a liberdade amorosa de Deus. É a liberdade de Deus que guia o lento caminhar da evolução. Assim, o ser humano é libertado do domínio da fatalidade e da repetição monótona e asfixiante da necessidade (natureza) ${ }^{40}$.

Criado à imagem de um Deus que escolhe o caminho da evolução para sua ação criadora-salvadora, o ser humano é chamado, num mundo e numa história humana, em evolução, inacabados, sujeitos ao mal e ao sofrimento, a reconhecer a realidade do pecado nele mesmo (vivendo o lento caminhar da conversão) e nas estruturas sociais, políticas, religiosas, econômicas..., se comprometendo na luta contra as injustiças e na vivência do amor-serviço concreto, sobretudo em relação às vítimas, como fez Jesus de Nazaré.

Importa muito ressaltar também que, à luz do poder humilde de Deus criador-salvador, deverá ser repensado o significado do poder humano. Convém perguntar: a criatividade e a liberdade são vividas para controlar e dominar os outros e o meio ambiente? Ou, ao contrário, elas são vividas para amar, para construir um mundo mais humano e para desenvolver um relacionamento mais harmonioso com todas as criaturas?

\section{Algumas Conclusões}

1. Não há contradição entre a fé em Deus criador e os resultados da ciência que estuda a evolução. Pode e deve existir complementação, mutuamente enriquecedora. Para isso, é indispensável evitar toda extrapolação do método científico ou teológico bem como o reconhecimento e a abertura a outros níveis de saber.

2. O diálogo crítico em relação à visão evolucionista, pode alargar e aprofundar a nossa visão de Deus. O Deus "pessoal" é o mesmo Deus da natureza e da evolução! O Deus da história é o mesmo Deus que continua criando!

${ }^{39}$ Cf. SEGUNDO, J. L., Que Mundo? Que Homem? Que Deus? op.cit., p.149-194.
${ }^{40}$ Cf. GESCHÉ, A., O ser humano, op. cit., p.53-89. 
Deus criador e salvador, dois aspectos da única realidade divina, realidade relacional: Deus, que é Amor em si mesmo, é também amor na relação com o ser humano, com cada uma das criaturas e com o universo inteiro. Deus todo-poderoso, sim, mas onipotente no amor, nunca na coerção e na imposição! Um Deus que em Jesus Cristo, voluntariamente e por amor, "deixa" espaço para que a criatura, as leis evolutivas e, especialmente, o ser humano possam ser eles mesmos.

3. O significado da humanização do ser humano fica, igualmente, enriquecido. É revalorizada a liberdade e a criatividade, vividas na solidariedade e no amor concreto, não no fechamento manipulador e dominador dos outros humanos e destruidor do meio ambiente. O ser humano visto como inacabado a caminho de "ser mais", aberto ao futuro, chamado a criar algo novo na história e no cosmos, aprendendo a lidar com a insegurança. Ser humano chamado, hoje, a tomar consciência do perigo que significa a defesa de uma ordem absolutizada (no nível social, político, religioso...), a repetição estéril do mesmo perigo, sem a abertura esperançosa ao futuro. Ser humano chamado a superar o individualismo e o subjetivismo fechados, asfixiantes, porque cortados da íntima vinculação existente com a complexidade das interrelações humanas, das inter-conexões com nosso eco-sistema vital e com o processo evolutivo; e cortado, no nível mais profundo, do Deus da Vida e do Amor (pecado). Ser humano chamado a orientar a "vontade de poder" para o serviço, a solidariedade e o amor efetivo concreto, superando a tentação, fortemente enraizada em todos os humanos, de viver o poder como controle e dominação.

4. Um desafio especial para os Institutos e as Faculdades de Teologia: é necessário aprofundar no diálogo crítico entre o mundo da fé e o mundo da ciência. É urgente desenvolver a teologia da natureza e da evolução, corrigindo a unilateralidade com que as dimensões pessoal, social e política têm sido analisadas. E algumas perguntas incômodas surgem aqui: não será a teologia estudada em nossas faculdades e institutos um tanto preguiçosa? Será que não é, em boa parte, uma teologia atrelada demais a questões e respostas que não coincidem com as suscitadas pelo mundo científico e cultural atual? Não estará faltando relevância e sobrando medo?

5. E, pastoralmente, parece cada vez mais necessário que se explique, para o povo cristão, os resultados da hermenêutica bíblica a respeito dos relatos bíblicos sobre a criação do mundo e do ser humano. Naturalmente, com uma metodologia adequada. 
-"Não tenhais medo" (Mt 28,5), nos fala hoje também o Senhor, vivo. O dom do Espírito supera o medo. Importa muito, para a credibilidade da mensagem da Igreja, enfrentar com coragem e discernimento os desafios da visão evolucionista do universo, da vida e do ser humano. Amém.

\section{Referências Bibliográficas}

BARBOUR, IAN G., When Science Meets Religion. Enemy, Strangers, or Partners?, NY: Harper Collins Publishers Inc., 2000.

BARROW, J. e TIPLER, F., The Anthropic Cosmological Principle. Oxford: Clarendon Press, 1986.

COLLINS, F. S., A linguagem de Deus. São Paulo, Ed. Gente, 2007, ed. 4,

DAWKINS, R., Deus, um delírio. São Paulo: Companhia das letras, 2007.

EDWARDS, D., El Dios de la evolución. Una teologia trinitaria. Santander: Sal Terrae, 2006.

ESTRADA, J. A., A impossivel teodicéia. A crise da fé em Deus e o problema do mal. São Paulo: Paulinas, 2004.

GARCIA RUBIO, A., Unidade na pluralidade. O ser humano à luz da fé e da reflexão cristãs. Paulus, 2006, 4 ed.

GESCHÉ, A., O Mal, em: Id., Deus para pensar. Vol. 1. São Paulo: Paulinas, 2003,

Id., O ser humano, em: Id., Deus para pensar. Vol. 2. São Paulo: Paulinas, 2003.

Id., O Cosmo. em: Id., Deus para pensar. Vol. 4. São Paulo: Paulinas, 2004.

HAIGHT, R., Dinâmica da teologia. São Paulo: Paulinas, 2004

HAUGHT, J. F., Deus após Darwin. Uma teologia evolucionista. Rio de Janeiro: José Olympio, 2002.

Id., Cristianismo e Evolução em 101 perguntas e respostas. Lisboa: Gradiva, 2009,

Id., J. F., Cristianismo e ciência, Para uma teologia da natureza. São Paulo: Paulinas, 2010.

MOLTMANN, J., Deus na criação. Doutrina Ecológica da Criação. Petrópolia: Vozes, 1992,

Id., El Espíritu de la vida: una pneumatología integral. Salamanca: Sígueme, 1998

PEACOCKE, A., Los caminos de la ciencia hacia Dios. El final de toda nuestra exploración. Santander: Sal Terrae, 2008.

POLKINGHORNE, J., Ciencia y Teologia. Una introdución. Santander: Sal Terrae, 2000. 
Id., Explorar la realidad. La interrelación de ciencia y religión. Santander: Sal Terrae, 2007.

QUEIRUGA, A. T., Recuperar la creación. Por una religión humanizadora. Santander: Sal Terrae, 1996.

Id., Fin Del cristianismo premoderno. Retos hacia un nuevo horizonte. Santander: Sal Terrae, 2000,

RANHER, K., Teología y ciencias naturales. Madrid:Taurus , 1967.

RATZINGER, J., Introdução ao cristianismo. Preleções sobre o Símbolo Apostólico. São Paulo: Herder, 1970.

SEGUNDO, J. L., J., L., Que mundo? Que homem? Que Deus? Aproximacões entre Ciência, Filosofia e Teologia. São Paulo-Paulinas, 1995,

TREVIJANO E., M., Fe y ciencia. Antropología. Salamanca, Sígueme, 1997

\section{Resumo}

Constatado o fato de que ainda perdura o conflito entre a visão evolucionista da vida e do cosmo, por um lado, e a fé bíblico-cristã em Deus criador, por outro lado, eu procuro neste artigo caminhos para a superação desse conflito, através da reflexão teológica. Para isso, em um primeiro ponto e de maneira muito resumida, apresento como se encontra, hoje, o estado da questão. Em um segundo ponto, abordo, também, sumariamente, o problema hermenêutico básico: a distinção necessária entre fé e expressão cultural (e religiosa) da fé. Enfim, no terceiro ponto, o mais central desse artigo, focalizo as principais pistas que a reflexão teológica atual está desenvolvendo para responder, de maneira positiva, ao desafio que a visão evolucionista lança, ao fazer teológico atual.

Palavras-Chave: Evolucionismo, Deus Criador, Ateísmo, Hermenêutica, Fé Cristã.

\section{Abstract}

Due to the fact that, on one hand, it still remains the conflict between the evolutionary view of life and the cosmos and on the other hand, the faith in the biblical-Christian in God the Creator, in this paper, I focus on ways to overcome this conflict, by means of theological reflection. First of all I offer a brief summary of the subject as it stands today, On a second point, I focus on the basic hermeneutic problem: a necessary distinction between faith and cultural expression (and religious) faith. Finally, the third point is the central topic of this paper, I discuss the main clues that theological reflection is now 
developing to respond, positively, to the challenge that the evolutionary view spread, when doing theology today.

Keywords: Evolutionism, Creator God, Atheism, Hermeneutics, Faith Christian.

Alfonso García Rubio

Doutor pela Pontifícia Universidade Gregoria de Roma Professor Emérito do Dept. ${ }^{\circ}$ de Teologia da PUC-Rio

E-mail: algaru@uol.com.br

Artigo Recebido em 07/01/2011

Artigo Aprovado em 28/02/2011 